\title{
Design of the user-side contract power transfer transaction mechanism considering adjustable loads
}

\author{
Junhong Guo ${ }^{1 *}$, Yining Liu ${ }^{1}$, Ling $\mathrm{Li}^{1}$, Xiaoqiang $\mathrm{Xue}^{1}$, Jingya $\mathrm{Su}^{2}$ and Haowen Ouyang ${ }^{3}$ \\ ${ }^{1}$ State Grid Jibei Electric Power Company Limited, Beijing, 100053, China \\ ${ }^{2}$ State Grid Shandong Electric Power Company Yantai Power Supply Company, 264000, China \\ ${ }^{3}$ Electrical and electronic engineering institute, Country North china electric power university, 102206, China
}

\begin{abstract}
In recent years, to cope with the increasing uncertainty of load side, the adjustability of load side is constantly improved. However, the power deviation of user side hasn't been well adjusted due to the lack of the channel. This not only makes users face higher risks, but also makes incomplete use of sufficient load side adjustable resources. One of the effective ways to solve the problems above is user-side contract power transfer transaction. In this paper, main forms of adjustable load in major fields are discussed at first, then the user-side contract power transfer transaction mechanism considering adjustable load is proposed, finally the validity of the proposed mechanism is verified by a study case.
\end{abstract}

\section{Introduction}

In recent years, the domestic electricity market reform has been deepened, the market scale has gradually expanded, and the number of users participating in the market has also continued to increase. However, the current demand for electricity by electricity users is affected by multiple factors such as the economic environment, industrial structure adjustments, energy conservation and emission reduction policies ${ }^{[1]}$, the progress of electricity market reforms, the new crown epidemic ${ }^{[2]}$, and China-US Economic and Trade Games. The uncertainty of user power consumption increases, and the difficulty of power load forecasting also improves. Faced with the everincreasing risk of the deviation power, the majority of market entities have strong demands for avoiding market risks. However, the current market for electricity consumption is relatively low in flexibility and lacks effective means to avoid power consumption deviation.

Central Committee and the State Council issued the Electricity Reform No.9 document in 2015. The document proposed many important measures to promote the electricity reform process, one of which is building an electricity forward market with active involvement by user side. The literature [3]-[8] studied the trading system, framework, business models, bidding strategies of the user side participating on power market transaction, which, to some extent enriched the transaction subject and model of the user-side market. On this basis, the promotion of electricity market reform and medium and long-term transaction conference held on September 28,2020 clearly points out that the contract power transfer transaction on the user side should be carried out. The premier of the transaction is that user side has the need to evade the risk of power deviation, while there are abundant adjustable loads to meet this demand. For users demand to power deviation risk aversion, the user has the motivation and demand to actively reduce the deviation power in advance for reducing the cost of the deviation power assessment, under the increasingly strict, standardized and refined deviation power assessment mechanism. For the reserve of adjustable loads, currently, the domestic load-side regulation resources with flexible adjustability are developing rapidly, such as distributed energy storage, electric vehicles (charging piles, charging station), regenerative electric heating, data center, air conditioning loads. Those show the huge potential of the use side to participate in system peak shaving, and also create bigger space for user-side contract power transfer transaction.

At present, the transfer trade of generation contracts has begun to take shape in the country, and the research on the transaction mechanism about the transfer trade of generation contracts has been relatively fully carried out [9-11]. However, the contract transfer trading on the power user side is in the process of brewing in most area, and the transaction mechanism also needs further research. Since the foreign countries have not specifically proposed the trading category of contract power transfer, there are few research results for reference. Some domestic scholars have already studied the trading mechanism and model of the contract power transfer transaction on the user side. For example, the literature [12] draws on PJM and put forward the trade varieties and trading mechanism of demand response in Guangdong electricity market. The literature [13] clarifies the work process of power consumption right trading between collaborative users. The literature [14] proposes electricity rights trading mechanism for orderly usage of electricity based on quota certificates. 
Contract power transfer transaction on the user-side is an important attempt to innovate electricity marketoriented development mechanism. It can not only enrich and improve the trading mechanism, maintain steady development of electricity market; but also provides users with effective means to evade power deviation and fully digs the vitality of peak shoving resources on the load side. This paper puts forward the design of user-side contract power transfer transaction mechanism considering adjustable loads, and verifies the rationality of proposed mechanism according to a case.

\section{The main forms of adjustable loads}

The main forms are shown in Figure 1. Compared with traditional loads, the load-side adjustable resources that can actively conduct demand response change the structure of load-side, and expand the transaction space of user-side market, which have already become an important part of the user-side.

5G Base Station
Distributed $=($ Station Energy Storage)
Energy Storage
Adjustable Load
Air Conditioning Rata Center
Charging Station (Pile)

Figure 1. The main form of adjustable load

\section{A user-side contract power transfer transaction mechanism considering adjustable loads}

\subsection{Participant}

Presently, electricity retailers and large users are the direct and main participants of user-side market, so they have rich transaction experience, at the same time, those two own abundant stocks of market contracts to trade, so the transaction space is large. According to above considerations, it regulates that user-side contract power transfer transaction should carry out between electricity retailers and large users who meet the admission requirement, particularly encourage the subjects who contain adjustable loads access to market. On the initial period of construction, medium and small enterprises are not allowed to directly participant, but can be represented by the electricity retailers.

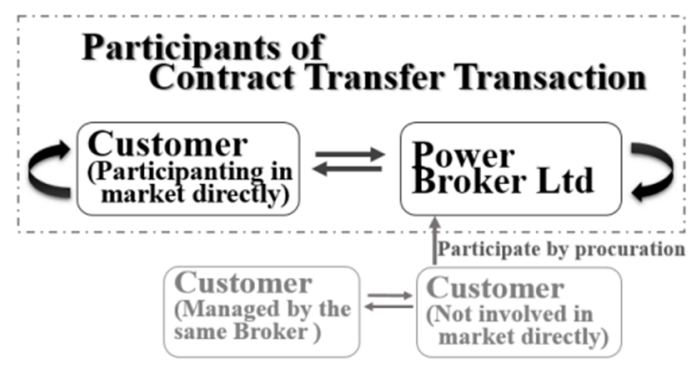

Figure 2. The main body of the user-side contract power transfer transaction market

\subsection{Trading Modes}

Bilateral consultation transactions, double hanging and double picking transactions, and centralized bidding transactions can be carried out according to the market actual demand. In the bilateral consultation transactions, the market subjects can only transfer or accept power during the same trading time. In the double hanging and double picking transactions, the market subjects can declare the transfer or accept power at the same time during the same trading time, but only the higher priority transactions can deal.

\subsubsection{Bilateral consultation transaction}

First, the bilateral negotiation transaction intention forms by the independent negotiation between market subjects, then the power trading platform can declare and confirm and the dispatching organizations conduct safety check. Finally, the result of the bilateral negotiation transaction is formed and the trading contract is signed.

\subsubsection{Double hanging and double picking transactions}

The market subjects submit the apply for listing transaction through transaction platform, including trading power and corresponding price. Other subjects independently delist. The system is responsible for recording transaction time and update the subject's list information automatically. The result takes effect after the dispatching organization conducting safety check.

\subsubsection{Centralized bidding transactions}

The market subjects declare the transfer power, price and other information through power transaction platform. The transaction center will rank the transferor and transferee in ascending order and descending order respectively. The market will be clearing at the uniform marginal price, that is, the average price of the transferor and transferee at the intersection of the quotation curve. This method can realize overall optimization, while provide market subjects with a relative clear price signal.

Centralized bidding transactions utilize the benefit maximization model, and the objective function is shown in formula (1). The transaction should comply with constraints such as transaction ceilings, system balance, and line flow, as shown in equations (2) $\sim(5)$.

$$
\begin{gathered}
\max \sum_{t=1}^{T} \sum_{i=1}^{m} \sum_{j=1}^{n} U_{i j . t}=\sum_{t=1}^{T} \sum_{i=1}^{m} \sum_{j=1}^{n}\left(C_{i . t}-C_{j . t}-C_{i j . t}\right) Q_{i j . t} \\
\text { s.t. } \sum_{i=1}^{m} Q_{i j . t} \leq Q_{j . t} \\
\sum_{j=1}^{n} Q_{i j . t} \leq Q_{i . t} \\
\sum_{i=1}^{m \prime} Q_{j j . t}=\sum_{j=1}^{n \prime} Q_{i j . t} \\
\left|\sum_{i=1}^{m}\left(P_{l, t}+\frac{\mu T}{24} Q_{i j . t}\right)\right| \leq P_{l}^{\max }
\end{gathered}
$$

In the formula, $U_{i j . t}$ is the social benefit generated by the transaction between transferor $i$ and transferee $j$ during trading period $t$ (the same below), $Q_{\mathrm{ij.t}}$ is the contract transferred from transferor $i$ to transferee $j, Q_{i . t}, Q_{j . t}$ is 
respectively, the transferor contract ceiling and the transferee adjustable load ceiling, $m$ and $n$ are the number of transferors and transferees respectively, $m$ ', $n$ ' are the number of the transferor and the transferee, respectively, $C_{i . t}, C_{j . t}$ are the quotations of the transferor $i$ and the transferee $j$ respectively, $C_{i k . t}$ is the transaction cost of the corresponding transaction. $P_{l, t}$ is the original power flow of the line $1, P_{l}^{\max }$ is the upper limit of power flow for line $l, \mu$ is the transfer coefficient.

\subsection{Transaction Organizations}

The transaction center can carry out user-side contract power transfer transaction in the cycle of year, quarter, monthly, week, or day-ahead according to the current situation of market construction. The ability of market subjects and the demand of arranging specific transaction mode should also be considered. The transaction sequence, transaction cycle and the division of market participants are shown in Figure 3.

\section{Annual/Quarterly/Monthly Transaction}

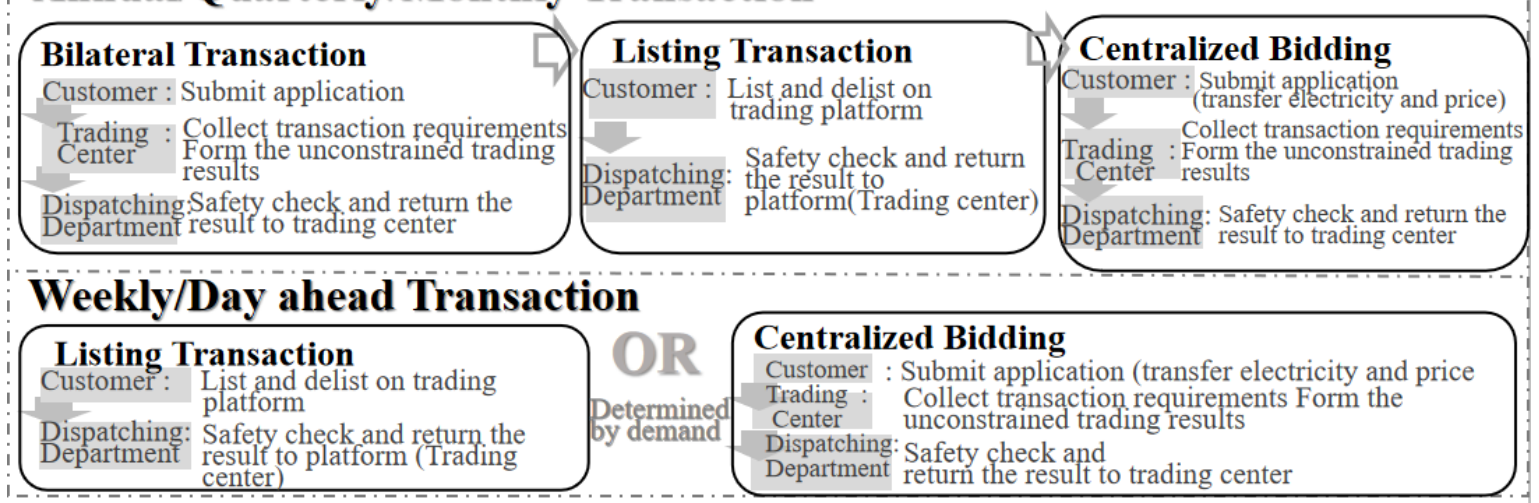

Figure 3. The trading period, order and duty of participants of each transaction method

The market subjects need to submit the declare of contract power transfer transaction through power transaction platform within the time specified in the trading announcement. Subsequently, the transaction centers are responsible to collect the trading needs, issue unconstrained trading results and send the result to dispatching organizations to conduct security check. After dispatching organizations finish the check, they feedback the result of check to transaction centers, provide the reasons why the transaction has not been passed, and make sure that the transactions which pass the check are executed.

\section{Case analysis}

Use the IEEE4 node model shown in Figure 4 to simulate the transaction model. After the results of bilateral consultation transactions and double hanging and double picking transactions are divided into a certain trading session (length is 1 hour), the change condition of subject power consumption plans, regulating ability and quotation information before centralized bidding transactions are shown in Table 1.The data in the table is randomly generated by Monte Carlo simulation based on cost information, When the transaction power is positive, it indicates that the user's power consumption deviation is negative and which hopes to transfer the power; otherwise, it indicates that the subject's power consumption deviation is positive and hopes to accept the power.

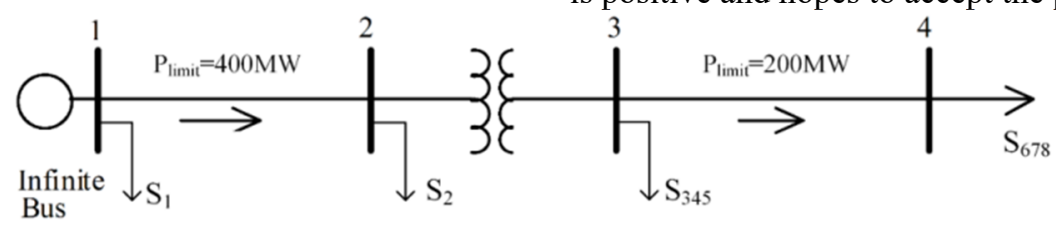

Figure 4. 4-node model

Table 1. Changes in the main power consumption plan and adjustment capacity (unit: $\mathrm{kW}$ )

\begin{tabular}{cccccccccc}
\hline $\begin{array}{c}\text { No. } \\
\begin{array}{c}\text { No- } \\
\text { de }\end{array}\end{array}$ & $\begin{array}{c}\text { Stock } \\
\text { contract }\end{array}$ & $\begin{array}{c}\text { Short- } \\
\text { term } \\
\text { forecast }\end{array}$ & $\begin{array}{c}\text { Adjustable } \\
\text { load type }\end{array}$ & $\begin{array}{c}\text { Original } \\
\text { adjusted } \\
\text { capacity }\end{array}$ & $\begin{array}{c}\text { Theoretical } \\
\text { trading power }\end{array}$ & $\begin{array}{c}\text { Transferred } \\
\text { contrast }\end{array}$ & $\begin{array}{c}\text { Down- } \\
\text { regulation } \\
\text { price }\end{array}$ & $\begin{array}{c}\text { Up-regulation } \\
\text { price }\end{array}$ \\
\hline 1 & 1 & 27.13 & 15.43 & Battery & {$[-2,7]$} & 4.70 & {$[0,4.7]$} & 230.35 & 317.23 \\
2 & 2 & 38.99 & 48.31 & Battery & {$[-3,7]$} & -6.32 & {$[-6.32,0]$} & 237.87 & 414.92
\end{tabular}




\begin{tabular}{|c|c|c|c|c|c|c|c|c|c|}
\hline 3 & 3 & 49.05 & 61.67 & - & - & -12.71 & {$[-12.71,0]$} & 241.41 & 331.17 \\
\hline 4 & 3 & 45.46 & 43.36 & Stored energy & {$[-5,4]$} & 0.00 & 7.09 & 284.13 & 294.97 \\
\hline 5 & 3 & 28.14 & 26.42 & $\begin{array}{c}\text { Air } \\
\text { conditioner }\end{array}$ & {$[-5,5]$} & 0.00 & {$[-3.3,6.7]$} & 265.84 & 269.80 \\
\hline 6 & 4 & 56.81 & 58.88 & Data centre & {$[-15,15]$} & 0.00 & {$[-17.1,12.9]$} & 186.91 & 249.20 \\
\hline 7 & 4 & 67.65 & 51.30 & - & - & 16.35 & {$[0,13.35]$} & 238.70 & 319.68 \\
\hline 8 & 4 & 32.21 & 36.50 & $\begin{array}{c}\text { Charging } \\
\text { station }\end{array}$ & {$[0,10]$} & -4.30 & {$[-4.3,0]$} & 263.23 & 349.01 \\
\hline
\end{tabular}

According to the theoretical transaction power, except $4,5,6$, other subjects all have the need to adjustment. Other subjects declare transaction volume and price according to power consumption deviation and adjusting ability. The transaction centre will arrange the transferor and transferee in ascending order and descending order respectively to form a quotation curve, as shown in Figure 2. the power flows of the two lines both meet the constraints. Therefore, the unconstrained result is the final result. The transferee power of subjects $2,3,4,5$ and the transferred power of subjects 1, 6 both deal. Because of the price mismatch, the conflict between the transferred power and the transferee power, the transferee power of subject 6 and the transferred power of subjects 4, 5 cannot deal. Due to the insufficient willingness of accepting, the subject 7 has $2.47 \mathrm{MW}$ of transferred power not traded. The final clearing price is the market unified marginal electricity price of 243.95 yuan/MW.

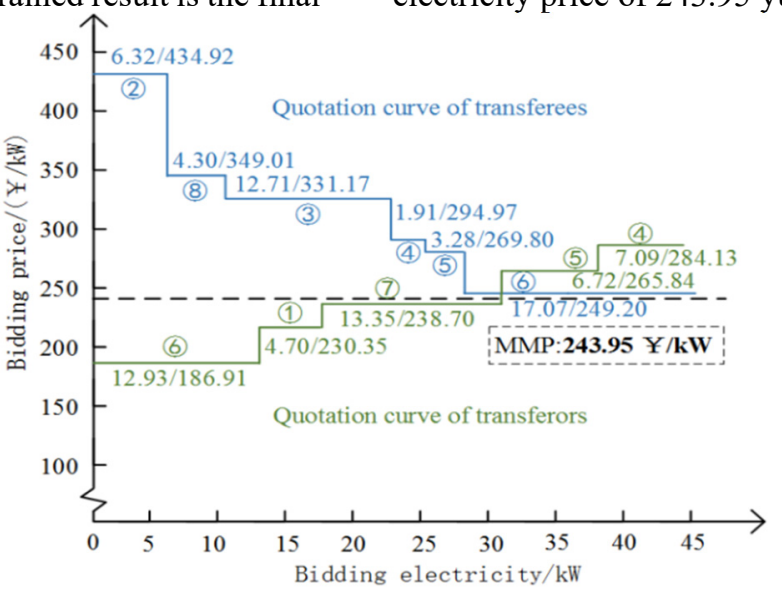

Figure 5. Transaction Results

Through the user-side contract power transfer transaction, the $28.86 \mathrm{MW}$ abandoned power in the original plan will consume by other power-deficient subjects. The adjustable load of $36.47 \mathrm{MW}$ is invoked, it not only offers effective method of risk aversion, but also deeply digs the vitality of peak shaving resources on the user-side.

\section{Conclusion}

The user-side contract power transfer transaction can not only be an effective method for users to reduce risk of contract deviation, but also make full use of user-side adjustable load resources. Main forms of adjustable load in major fields are discussed in this paper, then based on which, a user-side contract power transfer transaction mechanism considering adjustable load is proposed. In this mechanism, transaction subjects, trading modes and organizational form are defined clearly. Finally, the rationality of the mechanism is verified by a study case.

\section{Acknowledgments}

The authors are very grateful to State Grid Jibei Electric Power Company Limited for their support to the paper research, and to Professor Wang Yanling for her direction on the writing of the paper. The authors are also very thankful to the reviewers who made useful comments on an earlier version of the paper.

\section{References}

1. Wang Yanling, Wu Mengkai, Zhou Ziqing, Ma Hongyu. Quantitative analysis model of power load influencing factors based on improved gray correlation[J]. Power System Technology, 2017, 41(06):1772-1778.

2. Nie Xinwei, Shi Dan, Lin Tong. Analysis of the impact of the new coronavirus epidemic on my country's power industry[J].China Energy, 2020,42 (02):25-31+14.

3. M. Ghamkhari, H. Mohsenian-Rad and A. Wierman, "Optimal risk-aware power procurement for data centers in day-ahead and real-time electricity markets," 2014 IEEE Conference on Computer Communications Workshops (INFOCOM WKSHPS), Toronto, ON, 2014, pp. 610-615.

4. Z. Zhang, J. Guo, Z. Liu, J. Chen, F. Song and H. Zhang, "A smart collaborative structure for information centric retail electricity market," 2017 7th IEEE International Conference on Electronics 
Information and Emergency Communication (ICEIEC), Macau, 2017, pp. 369-372.

5. Zheng Yanchong, Yu Hang, Shao Ziyun, Jian Linni. Day-ahead bidding strategy for electric vehicle aggregator enabling multiple agent modes in uncertain electricity markets[J]. Applied Energy,2020,280.

6. Mahdi Behrangrad. A review of demand side management business models in the electricity market $[\mathrm{J}]$. Renewable and Sustainable Energy Reviews,2015,47.

7. X. Ge, K. Li, F. Wang and Z. Mi, "Day-ahead Market Optimal Bidding Strategy and Quantitative Compensation Mechanism Design for Load Aggregator Engaging Demand Response," 2019 IEEE/IAS 55th Industrial and Commercial Power Systems Technical Conference (I\&CPS), Calgary, AB, Canada, 2019, pp. 1-8.

8. Q. Tang, X. Wu, S. Dong and R. Ma, "Framework Design of Load Aggregators Participating in Electricity Market," 2018 2nd IEEE Conference on Energy Internet and Energy System Integration (EI2), Beijing, 2018, pp. 1-6.

9. Xu Haoliang, Jin Panrun, Jiang Jiheng, Lu Zongxiang, Qiao Ying. Optimization Method for Power Generation Rights Transaction to Promote Wind Power Consumption[J].China Electric Power, 2020, 53(03):167-176.

10. Liu Chuang, Li Fengting, Chao Qin, Wang Xinghao. A new model of multilateral power generation rights trading considering clean energy consumption[J]. Electric Power Automation Equipment, 2021,41(01):92-98.

11. Junhong Guo, Ling Li, Yajie Li, Jingya Su. Analysis on Market Potential of Generation-side Contract Electricity Transfer Transaction [A]. In: 2020 IEEE 4th Conference on Energy Internet and Energy System Integration (EI2) [C]. Wuhan China: IEEE,2020.

12. Yang Wei, Zeng Zhijian, Chen Haoyong, Wang Fang, Guo Manlan. Research on Guangdong Electricity Market Demand Side Response Transaction Mechanism[J].Guangdong Electric Power,2017,30(05):25-34+68.

13. T. Kang and H. Kim, "Preserving privacy with anonymity for customer collaboration in smart grid," 2012 18th Asia-Pacific Conference on Communications (APCC), Jeju Island, 2012, pp. 724729, doi: 10.1109/APCC.2012.6388290.

14. Gao Ciwei, Li Qianyu, Song Hongkun. A new mechanism for orderly electricity consumption based on electricity rights trading $[\mathrm{J}]$. Electricity Demand Side Management,2013,15(03):5-10. 